\title{
Chemical Constituents of Salvia aegyptiaca
}

\author{
Salem A. Basaif \\ Chemistry Department, Faculty of Science, \\ King Abdulaziz University, Jeddah, Saudi Arabia
}

\begin{abstract}
AвSTRACt. The essential oil of Salvia aegyptiaca was analysed by GC/ MS technique. Eighteen compounds were identified. It was found that the essential oil comprises $40 \%$ terpenoidal constituents, opposite to $32 \%$ fat derivatives. The major terpenoidal component was 1(10)aristolene (19.3\%).

From the non-volatile matter, $\beta$-amyrin, lupeol, $\beta$-sitosterol, stigmasterol, $\beta$-sitosterol- $\beta$-D-glucopyranoside and stigmasterol- $\beta$-Dglucopyranoside as well as $3 \alpha$-hydroxy-24-alkylcarboxylate-12oleanan-28-oic acid. Fatty acids esters were isolated and identified by spectral means.
\end{abstract}

Key words: Salvia aegyptiaca; Mentheae; Labiatae; Essential oil; Oeanane triterpenoids; Sterols.

\section{Introduction}

Salvia L. (Tribe Mentheae), with over than 900 species $^{[1]}$, is one of the larger genera in the Labiatae (Lamiaceae). The genus was divided ${ }^{[2]}$ into four subgenera: Salvia, Sclarea, Leonia and Calosphace. While subgenera Salvia and Sclarea are primarily Asiatic and European, and species of subgenus Leonia are reported in north America, Salvia subgenus Calosphace is exclusively Central and South American.

The genus Salvia comprises many medicinal plants. In Kuwait S. aegyptiaca is used for treating eye diseases ${ }^{[3]}$. In the Canary Islands $S$. canariensis is prescribed as a diuretic ${ }^{[4]}$. S. fruticosa is drunk as tea in Israel to relieve headaches and abdominal pains, while a herbal bath prepared with the herb is used to relieve rheumatism $^{[5]}$. In Jordan it is used to relieve indigestion ${ }^{[6]}$. In Iraq S. aegyptia is used in diarrhoea, genorrhoea, haemorrhoids and in eye diseases ${ }^{[7]}$. Both S. lavandulifolia and $S$. officinalis is used in the traditional medicine as an antidiabetic ${ }^{[8]}$. 
Although Salvia is very large genus, phytochemical data is available for only a relatively small number of species. The presence of abietane and clerodane diterpenoids may be considered as a generic character. There seems to be clearly phytochemical differentiation between subgenera Salvia, Sclarea and Leonia on the one hand, and the American subgenus Calosphace on the other ${ }^{[9]}$.

The percentage of essential oil corresponds remarkably well with Erdtman's two subfamilies; the Nepetoideae (oil-rich $>0.5 \%$ of dry weight) and the Lamioideae (oil- poor $<0.1 \%$ of dry weight). Iridoid glycosides occur in the Lamioideae but are absent in the Nepetoideae. Salvia is an exception to those general rules. It belongs to the subfamily Nepetoideae, but many Salvia species are oil- poor and contain iridoids ${ }^{[10]}$.

Pentacyclic triterpenoids are common in Salvia spp. ${ }^{[11]}$. Both $\alpha$ - and $\beta$ amyrins were found in S. amplexicaulis and S. apiana ${ }^{[12]}$.

In this article, we present the identification of the constituents of the essential oil as well as the isolation of some triterpenoids and sterols from the nonvolatile matter of $S$. aegyptiaca, that was investigated previously only for abietane diterpenoids ${ }^{[13]}$.

\section{Experimental}

General: GC/MS spectra were taken on QP-7000 Shimadzu, with a fused silica capillary column $(30 \mathrm{~mm} \times 0.25 \mathrm{~mm}$ ID), film $(5 \%$ phenyl, $95 \%$ methylsilicon) thickness $0.25 \mu$, injector temp. $250^{\circ} \mathrm{C}$, temp. program: $50^{\circ} \mathrm{C}$ for $5 \mathrm{~min}$,, starting from $100^{\circ} \mathrm{C}$ in rate $5^{\circ} \mathrm{C} / \mathrm{min}$. for 5 mins', starting from $150^{\circ} \mathrm{C}$ in rate $5^{\circ} \mathrm{C} / \mathrm{min}$. for 5 mins', starting from $200^{\circ} \mathrm{C}$ in rate $5^{\circ} \mathrm{C} / \mathrm{min}$. for $5 \mathrm{mins}$, starting from $250^{\circ} \mathrm{C}$ in rate $5^{\circ} \mathrm{C} / \mathrm{min}$. for 5 mins', equil. Time $5-35$ mins', and the output is an IBM computer with software class 5000 and NIST library for comparison; ${ }^{1} \mathrm{H}$ NMR spectra were taken on Bruker FT-NMR $400 \mathrm{MHz}$, using $\mathrm{CDCl}_{3}$ as a solvent.

The plant material: Salvia aegyptiaca L., in the flowering stage, was collected in January 2001 from Taief-Al Baha road, $50 \mathrm{~km}$ from Taief, and identified by Prof. Dr. A. Faied, Botany Department, King Abdulaziz University, Jeddah. A voucher specimen was deposited on the Herbarium of Botany Department, King Abdulaziz University.

Processing of plant material: Fresh whole plant, including the root $(775 \mathrm{~g})$ was soaked at room temperature in diethyl ether/methanol 1:1 for $24 \mathrm{~h}$. The extract, obtained by filtration was concentrated to half its volume and steam distilled. The distillate was extracted with diethyl ether to give the essential oil $(0.26 \mathrm{~g})$, which is yellowish in colour, with the same odour of the plant. The 
steam non-volatile components were extracted by $\mathrm{CHCl}_{3}$ to give $39 \mathrm{~g}$ crude extract, which was defatted by dissolving in methanol, cooling, filtration and finally evaporated to give the defatted extract (18 g).

Separation of the compounds: The components of the essential oil were separated and identified by GC/MS technique. The non-volatile constituents (18 g) were separated on silica gel CC into four fractions (Sal-Sa4). Fraction Sal (3.2 $\mathrm{g}$, eluted by pet. ether/ether 3:1) contained fats. Fraction Sa2a (2.9 g, eluted by pet. ether/ether 1:1) gave by TLC, $40 \mathrm{mg}$ of which (silica gel, pet. ether/ether 3:2) 7 (12 mg, $\mathrm{R}_{\mathrm{f}}$ 0.61) and lupeol (18 mg, $\mathrm{R}_{\mathrm{f}}$ 0.52). Fraction Sa2b (1.7 g, eluted after $\mathrm{Sa} 2 \mathrm{a}$ by the same solvent system) afforded a mixture of $\beta$-sitosterol and stigmasterol (2:1). Fraction Sa3 (1.9 g, eluted by pure ether) gave, $60 \mathrm{mg}$ of which, by TLC (silica gel, pet. ether/ether 1:4) $8\left(38 \mathrm{mg}, \mathrm{R}_{\mathrm{f}} 0.68\right)$ in addition to fats. Fraction Sa4 (2.1 g, eluted by ether/methanol 9:1) gave a mixture of $\beta$ sitosterol- $\beta$-D-glucopyranoside and stigmasterol- $\beta$-D-glucopyranoside $(2: 1)$.

\section{Results and Discussion}

\section{Identification of the Volatile Constituents}

Identification of the constituents of the essential oil was achieved by using GC/MS technique which resulted in identification of fourteen components. The proposed structures were confirmed by comparing the MS spectra with authentic ones ${ }^{[14]}$. The results were tabulated in Table 1. From the table we can conclude that the essential oil of $S$. aegyptiaca comprises $40 \%$ terpenoidal constituents opposite to $32 \%$ fat derivatives and the major tepernoidal component is 1(10) aristolene (19.29\%).

\section{Identification of the Non-volatile Constituents}

In addition to the known compounds b-amyrin $\mathbf{8}^{[12]}$, lupeol, $\beta$-sitosterol, stigmasterol, $\beta$-sitosterol- $\beta$-D-glucopyranoside and stigmasterol- $\beta$-D-glucopyranoside $^{[15]}$, the chromatographic separation of the non-volatile material afforded a mixture of fatty acid esters of an oleanane triterpenoid 7.

${ }^{1} \mathrm{H}$ NMR of 7 gave a triterpenoid pattern of signals with six singlets from $\delta$ 0.8 to $\delta 0.9$ ppm. A multiplet at $\delta 2.81$, together with a broad singlet at $\delta 5.28$, typical of H-18 and H-12 of oleanolic acid derivatives were viewed in the spectrum. A pair of doublets with gem coupling of $14 \mathrm{~Hz}$ at $\delta 4.15$ and $\delta 4.17$, was in agreement with 24-alkyl carboxylate ester. This was coincident with the presence of fatty acids signals in the spectrum. A multiplet of $\mathrm{H}-3$ was found at $\delta$ 3.21 , in agreement with fatty acid ester of $3 \alpha$-24-dihydroxy-12-oleanan-28-oic acid, that was isolated previously in the form of the free diol from Salvia nicolsoniana $^{[16]}$. 
TABLE 1. GC analytical data of the essential oil of S. aegyptiaca.

\begin{tabular}{|c|c|c|c|}
\hline Peak no. & $\mathrm{R}_{\mathrm{t}}(\min )$ & $\%$ & Identification \\
\hline 1 & 6.18 & 1.14 & Aromadendrene 1 \\
\hline 2 & 6.35 & 19.29 & 1(10) Aristolene 3 \\
\hline 3 & 6.48 & 6.14 & Butylated hydroxytoluene* \\
\hline 4 & 6.57 & 5.71 & $\gamma$-Elemene 5 \\
\hline 5 & 6.81 & 3.43 & 9-Aristolene 4 \\
\hline 6 & 8.24 & 1.29 & Alloaromadendrene 2 \\
\hline 7 & 8.59 & 18.43 & Diphenyl amine* \\
\hline 8 & 12.96 & 1.71 & Phthalate ester ${ }^{\#}$ \\
\hline 9 & 13.35 & 2.43 & 1-Hexadecanol \\
\hline 10 & 14.21 & 10.57 & Methyl palmitate \\
\hline 11 & 15.03 & 7.00 & E,E,E-Cembrene A 6 \\
\hline 12 & 17.48 & 3.71 & Methyl linoleate \\
\hline 13 & 17.59 & 8.00 & Methyl linolenate \\
\hline 14 & 17.79 & 2.00 & Phytol \\
\hline 15 & 19.51 & 1.57 & Hexadecane \\
\hline 16 & 20.40 & 1.43 & Phthalate ester ${ }^{\#}$ \\
\hline 17 & 21.34 & 2.86 & Octadecane \\
\hline 18 & 23.39 & 3.00 & Eicosane \\
\hline
\end{tabular}

${ }^{*},{ }^{\#}$ Contaminants from the solvent; ${ }^{*}$ antioxidant, ${ }^{\#}$ plasticizer.

Known compounds were identified by comparing their ${ }^{1} \mathrm{H}$ NMR spectra with authentic ones. 


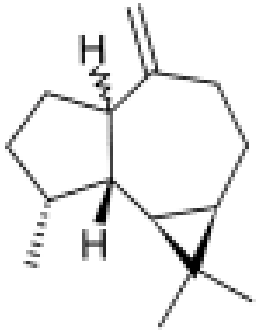

$1 ; l \alpha \mathrm{H}$

2; $1 \beta \mathrm{H}$

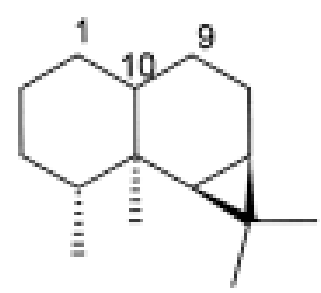

3; $\Delta^{\mathrm{t}(10)}$ 4; $\Delta^{9}$

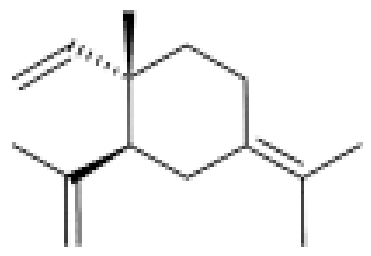

5

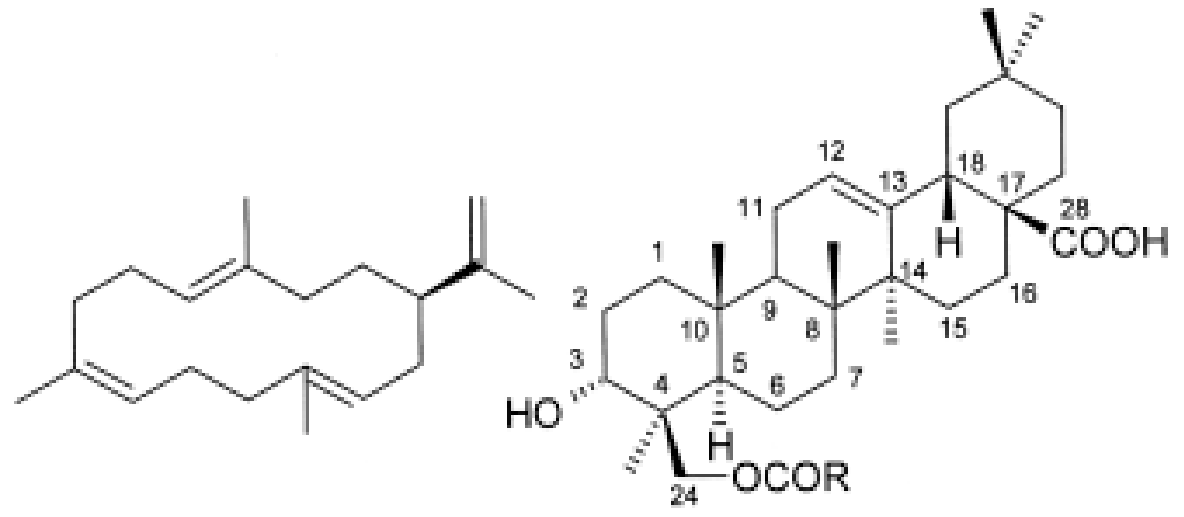

6

$7 ; \mathrm{R}=$ alkyl groups of fatty acids

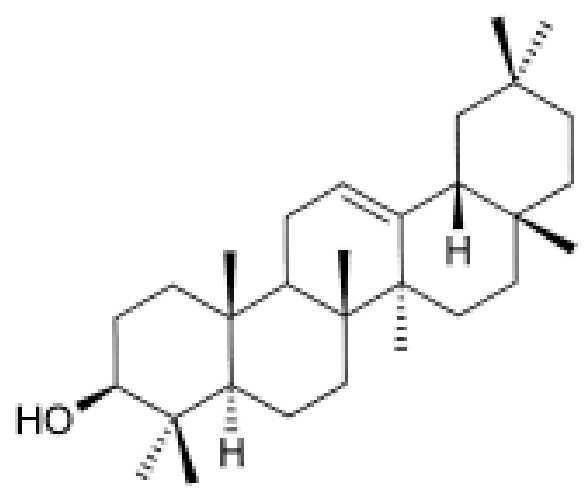

8 


\section{References}

[1] Standley, P. and Williams, L., Fieldiana, Bot., 24: 327 (1973).

[2] Bentham, G., Labiatae. In G. Bentham \& J.D. Hooker (editors), General Plantarum, Vol. 2: 1160, Reeve \& Co., London (1876).

[3] Alami, R., Macksad, A. and El-Gindy, A., Medicinal Plants in Kuwait, p. 137, Kuwait (1975).

[4] Darias, V., Bravo, L., Rabanal, R., Sanchez, C., Gonzalez, R. and Hernandez, A., J. Ethnopharmacol. 25: 77 (1989).

[5] Palevitch, D., Yaniv, Z., Dafni, A. and Friedman, J., Medicinal Plants of Israel. In L. Craker \& J. Simons (editors). Herbs, Spices and Medicinal Plants, Vol. I: 281, Oryx Press, Phoenix, Ariz. (1986).

[6] Karim, F. and Quraan, S., Medicinal plants of Jordan, p. 190, Yarmouk University (1986).

[7] Al-Rawi, A. and Chakravaty, H.L., Medicinal Plants of Iraq, Government Press, Baghdad (1964).

[8] Bailey, C.F. and Day, C., Diabetes Care, 12: 553 (1989).

[9] Rodriguez-Hahn, L., Esquivel, B., Cardenas, J. and Ramamorrthy, T.P., The Distribution of Diterpenoids in Salvia. In R.M. Harley \& T. Reynolds (editors). Advances in Labiate Science, p. 335, Royal Botanic Gardens, Kew (1992).

[10] Richardson, P.M., The Chemistry of Labiatae. In R.M. Harley \& T. Reynolds (editors). Advances in Labiatae Science, p. 291, Royal Botanic Gardens, Kew (1992).

[11] Rizk, A.M., The Phytochemistry of the Flora of Qatar, p. 210, Scientific and Applied Research Center, University of Qatar (1986).

[12] Ulubelen, A., Brieskorn, C.H. and Oezdemir, N., Phytochemistry, 16: 790 (1997).

[13] Sabri, N.N., Abou-Donia, A.A., Ghazy, N.M., Assad, A.M., El-Lakany, A.M., Sanson, D.R., Gracz, H., Barnes, Ch.L., Schlemper, E.O. and Tempesta, M.S., J. Org. Chem. 54: 4097 (1989).

[14] Adams, R.P., Identification of Essential Oil Components by GC/MS, Allured Publishing Corporation, Carol Stream, Illinois, USA (1995).

[15] Dawidar, A.M., Metwally, M.A., Abou-Elzahab, M. and Abdel-Mogib, M., Pharmazie, 45: 70 (1990). 


\title{
المكونات الكيميائية لنبات سالفيا إيجيبتياكا
}

\author{
سالم أحمد باسيف

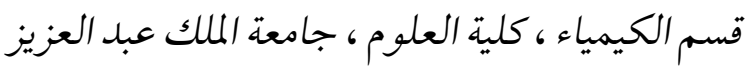

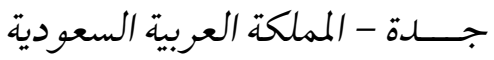

المستـخلص. في هذا البـحث تم تحليل الزيت الطيـار لنبـات سـالفيـا

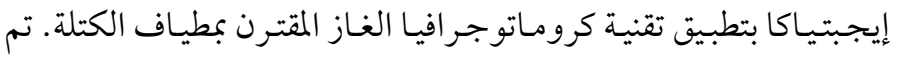

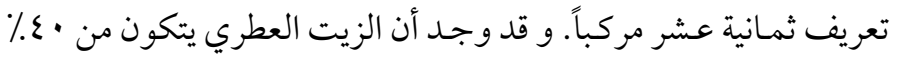

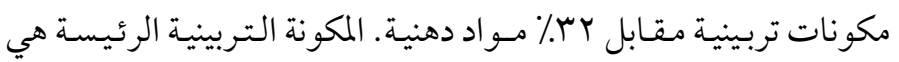

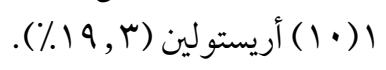

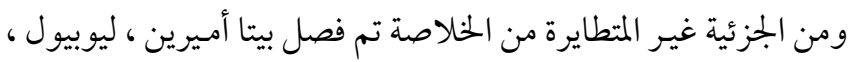

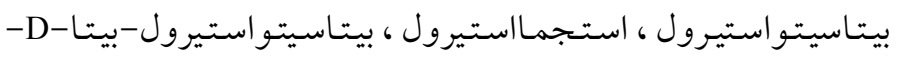

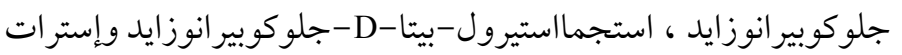

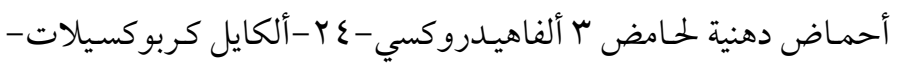

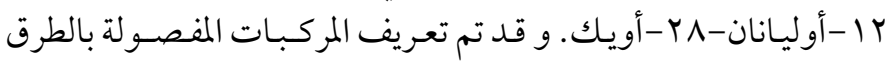
الطيفية (آو 